\title{
Drought Assessment of Eastern Satara District of Maharashtra Using Rainfall Anomaly Index
}

Prakash T Waghmare ( $\Delta$ prakashgeo89@gmail.com )

Shivaji University

Sachin S Panhalkar

Shivaji University

Somanath D Pawar

Shivaji University

Research

Keywords: Rainfall Anomaly Index (RAI), Drought, GIS, potential sites, etc.

Posted Date: August 7th, 2020

DOI: https://doi.org/10.21203/rs.3.rs-52305/v1

License: (1) This work is licensed under a Creative Commons Attribution 4.0 International License.

Read Full License 


\title{
Drought Assessment of Eastern Satara District of Maharashtra Using Rainfall Anomaly Index
}

\begin{abstract}
Drought is universally acknowledged as a phenomenon associated with scarcity of water. Proper assessment of rainfall is an essential need to reduce the intensity of drought. Present work aims study the space-time variation in the rainfall of the eastern part of the Satara district of Maharashtra using the Rainfall Anomaly Index (RAI). Daily precipitation data of sixteen meteorological stations were used for the period between 1979 and 2013. RAI was calculated and plotted in spatial distribution maps. The overall investigation reveals that the eastern and southern part of the study area is prone to dry condition. The present investigation is useful to delineate potential sites of drought and through this study risk of future drought conditions can be curtailed.
\end{abstract}

Keywords: Rainfall Anomaly Index (RAI), Drought, GIS, potential sites, etc.

\section{Introduction}

Drought is a complex hydrologic extreme, which has an extensive impact on various fields such as agriculture, water resources (water scarcity), and ecosystems. Drought is one of the most disastrous climatic hazards affecting several areas throughout the world. (Wilhite 2000). The meteorological drought is defined as the degree of dryness which quantified by insufficiencies of precipitation and the time of the dry spell. (WMO, No.989, 2005: Schuman, 2007). Drought is an environmental disaster which effects on environmental components such as hydrosphere, atmosphere and biosphere, corresponding to water, air and life respectively. Drought effects on groundwater as a result in crop failure, lack of water supply, declined water quality, reduced power generation. Drought is characterized by frequency, threshold intensity and duration. It also studied from three angles depending on influential aspects such as precipitation, evaporation, the moisture of soils, vegetation, and streamflow. (Ionita et al. 2016; Rajasekaran et al. 2018). For the first type, based on rainfall and evaporation, it represents the meteorological drought. The second, based on soil moisture and vegetation, it refers to agricultural drought. The third group, based on stream flow, represents hydrological drought.

The Indian economy is mainly based on agriculture, as nearly about $70 \%$ of the total population is dependent on livelihood. India receives about $75-90 \%$ of the annual rainfall in the four months of the year due to the southwest monsoon. Both spatial and temporal uncertainties and irregularity in monsoon precipitation, droughts frequently occurs in many part of the country. The net sown area of the country is approximately 140 million ha. out of that 68 per cent area is vulnerable to drought and 50 per cent area is classified as severely drought prone (Kamble, Ghosh, Rajeevan, \& Samui, 2010). Knowledge of the likelihood of occurrence of droughts including duration, severity, intensity and spatial extent is significant in planning as well as 
management of scarce water resources. Drought indices are used to compare the spatial and temporal variability of historical droughts with the current situation, and thus provide policymakers a tool for measuring drought events and measuring drought impacts.

Drought indices are important tool for monitoring and assessing droughts as they facilitate complex interrelationships between multiple climatic parameters (Palmer 1965).In recent times, researchers and various organizations have developed different drought indices to assess drought such as palmer drought severity index (PDSI), rainfall anomaly index (RAI), crop moisture index (CMI), surface water supply index (SWSI), standardized precipitation index (SPI), temperature vegetation drought index (TVDI), modified temperature vegetation drought index (mTVDI), and many more (Palmer 1965, 1968; Dai 2011; McKee et al. 1993; Sandholt et al. 2002; Shafer and Dezman 1982; Van Rooy 1965, 2015; Wells et al. 2004; Zhao et al. 2017; WMO and GWP 2016).The Rainfall Anomaly Index (RAI), developed by Rooy (1965), is used to classify the positive and negative severities in rainfall anomalies. It is considered as an index of remarkable procedural simplicity because it requires only precipitation data (Freitas, 2005; Fernandes et al., 2009). The RAI offers a higher degree of transparency and tractability and demands a lower degree of sophistication than the SPI with regard to the evaluation criteria for drought indices as proposed by Keyantash and Dracup (2002). According to Rooy (1965), RAI aims to make the comparison between precipitation deviations in different regions feasible. The present study has been carried out to assess the intensity and frequency of drought using RAI for the eastern Satara District of Maharashtra.

\section{Study Area}

The study area in this work concerns drought-prone area of the eastern Satara district of Maharashtra (Fig.1). The study area has tropical monsoon type climate. There are mainly four seasons in study area, Cold season from December to February, Hot season from March to May, Southwest monsoon season from June to September, and Post monsoon or the retreating monsoon season from October and November. The area experiences the semiarid climate with a hot summer and dry season throughout the year except during the south-west monsoon season. The summers are hot and become more humid in their later part with temperatures reaching as high as $38^{\circ}$ in the month of May. The monsoon starts in the month of June and extends till September. The rainfall is brought by South West monsoon winds. Winters are between maritime temperate and semi-tropical with temperatures ranging from $14^{\circ}$ to $30^{\circ}$. The mean annual precipitation over the study is about $975 \mathrm{~mm}$. It extends between $17^{0} 22^{\prime} 57^{\prime \prime}$ to $18^{0} 6^{\prime} 03^{\prime}$ " North latitude and $74^{0} 09^{\prime} 38^{\prime}$ " to $74^{0} 55^{\prime} 32^{\prime}$ ' East longitude. The total area of the proposed study is $3894 \mathrm{~km}^{2}$ and it comprises Man, Khatav and Phaltan tehsils of Satara district. The average height of the study area is about 713 meters. The maximum height is 1004 meters which is observed towards the western part of the study area. The lowest elevation is observed towards the extreme east part where the height is 423 meters. 


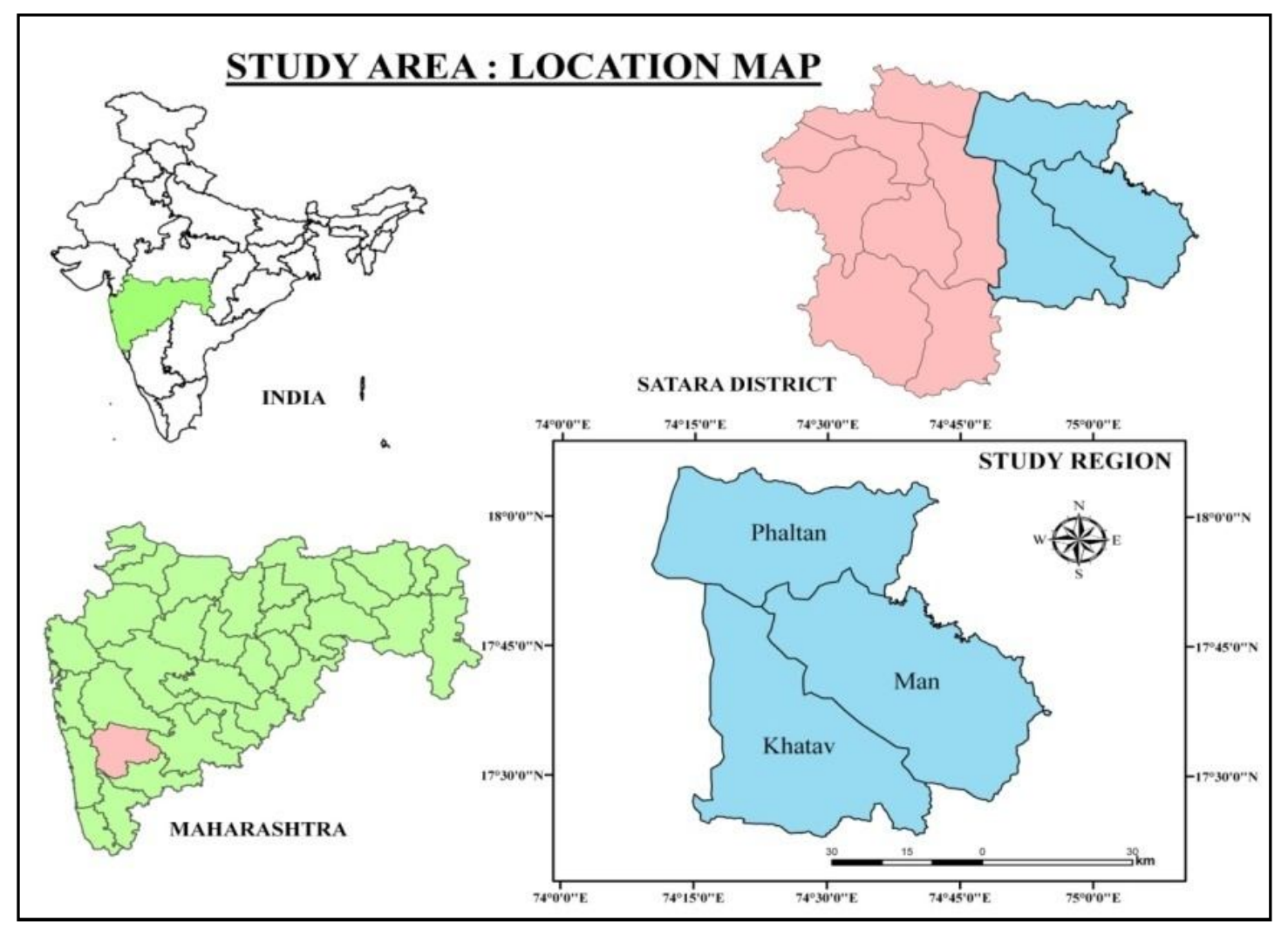

Fig.1: Geographical Location of the Study Area

\section{Research Methodology}

The database used in this study is of 16 meteorological stations for 35 years (1979-2013). The rainfall data was collected from the Indian Meteorological Department (IMD), Pune. From the precipitation data, the Annual Rainfall Anomaly Index (RAI) was calculated to analyze the frequency and intensity of the dry and rainy years in the studied area. In addition, the monthly RAI was calculated for specific years of the historical series aiming to analyze the distribution of rainfall in the years of greatest anomaly.

RAI, developed and firstly used by Rooy (1965) and adapted by Freitas (2005), constitutes the following equations:

RAI $=3 \quad\left[\frac{\mathrm{N}-\mathrm{N}}{\overline{\mathrm{M}}-\mathrm{N}}\right]$ For positive anomalies .............

$\mathrm{RAI}=-3\left[\frac{\mathrm{N}-\mathrm{N}}{\mathrm{X}-\mathrm{N}}\right]$ For negative anomalies..............2

Where: $\mathrm{N}=$ current monthly/yearly rainfall, in order words, of the month/year when RAI will be generated $(\mathrm{mm}) ; \bar{N}=$ monthly/yearly average rainfall of the historical series $(\mathrm{mm}) ; \bar{M}=$ average 
of the ten highest monthly/yearly precipitations of the historical series $(\mathrm{mm}) ; \bar{X}=$ average of the ten lowest monthly/ yearly precipitations of the historical series (mm); and positive anomalies have their values above average and negative anomalies have their values below average.

Table 1: Classification of Rainfall Anomaly Index Intensity

\begin{tabular}{|c|c|c|}
\hline \multirow{7}{*}{$\begin{array}{l}\text { Rainfall Anomaly } \\
\text { Index (RAI) }\end{array}$} & RAI range & Classification \\
\hline & Above 4 & Extremely humid \\
\hline & 2 to 4 & Very humid \\
\hline & 0 to 2 & Humid \\
\hline & -2 to 0 & Dry \\
\hline & -4 to -2 & Very dry \\
\hline & Below -4 & Extremely dry \\
\hline
\end{tabular}

Source: Freitas (2005) adapted by Araújo et al. (2009)

The result was plotted in a spatial distribution map in the Arc GIS 10.5 Software, by applying the Kriging method.

\section{Result and Discussion}

\section{Distribution of annual rainfall}

The average annual distribution of rainfall of the sixteen stations of the study area is shown in figure2. The box plot represents annual average rainfall variability in the rainfall stations over the period 1979-2013 to describe the behavior of annual rainfall in the study area. Each box includes a middle $50 \%$ of the data. The median values are displayed as line and mean value is displayed with $\square$ symbol. The top and bottom of the box represent the inter-quartile ranges (25$50 \%$ and 50-75\%). The lines extended above and below in the box mark the maximum and minimum values that fall within acceptable range respectively (Sabrine et al. 2018). The mean annual rainfall ranges from $267 \mathrm{~mm}$ to $2089 \mathrm{~mm}$ at station 12 and 1 respectively. The high and irregular variability in the distribution of rainfall is depicted with alternating wet and dry periods over the entire study area (Fig.2). 


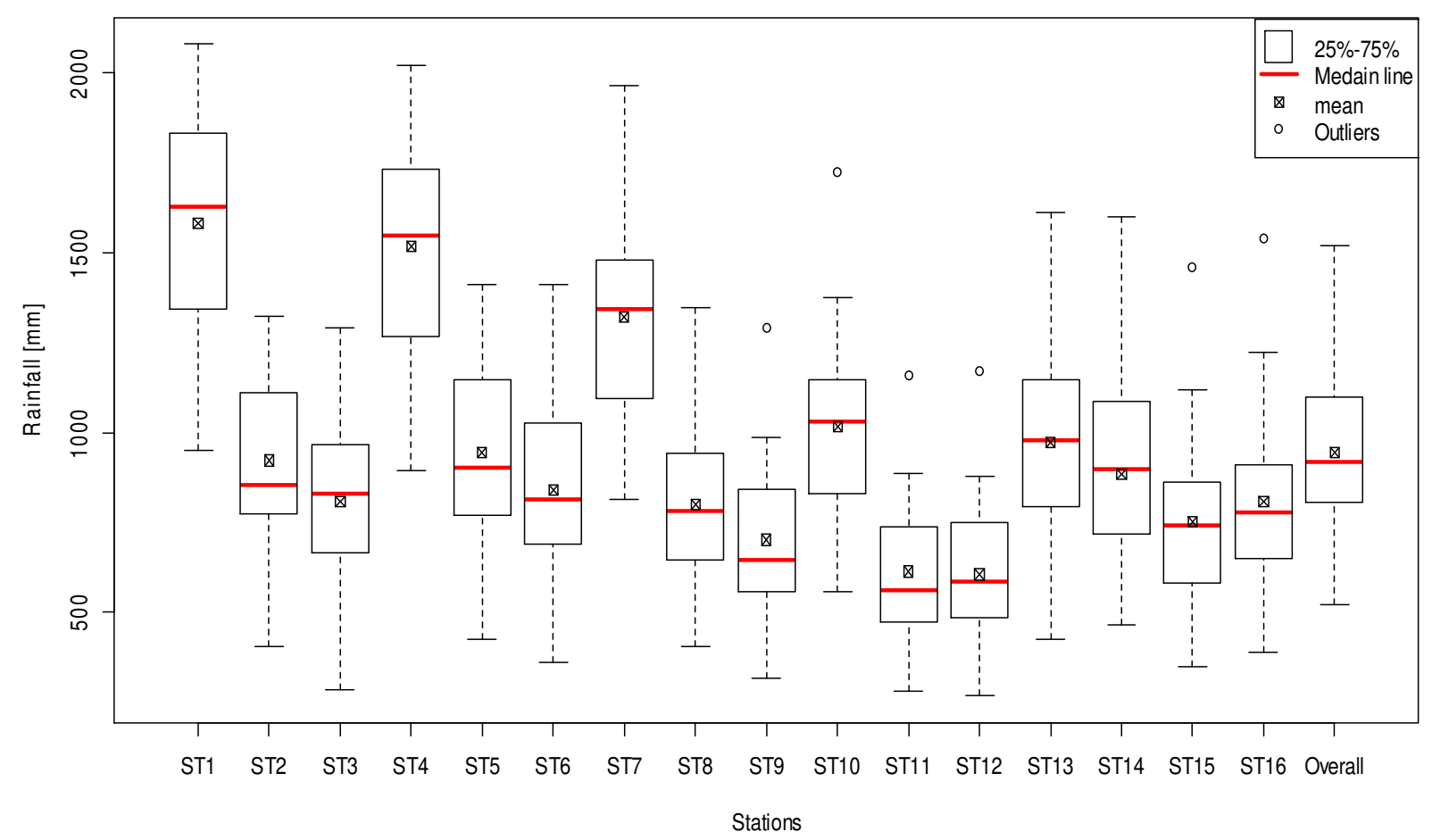

Fig.2: Box plot of annual rainfall variability for every station and overall study area (1979-2013)

\section{Analysis of RAI}

The drought years and the rainy years, during the period from 1979 to 2013, can be analyzed through RAI (Figure3). It enables to identify periods where these events were more extreme and/or mild. The positive values observed in Figure3 represent rainy or wet years and the negative values represent the dry years, with different degrees of intensity. The occurrence of 16 years with a positive RAI, varying from extremely wet to humid, and 19 years with a negative RAI, varying between very dry and dry was observed. In other words, there were more years of drought than rainy ones. The periods that remained the longest with droughts were from 1982 to 1988, from 2000 to 2005, and from 2011 to 2012 (Figure3). 1992 was the year with the highest negative value, with a RAI of -5.33 , classified as extremely dry. The year of greatest positive value was 1990 , with an average RAI of 7.12 , being therefore classified as extremely humid. 


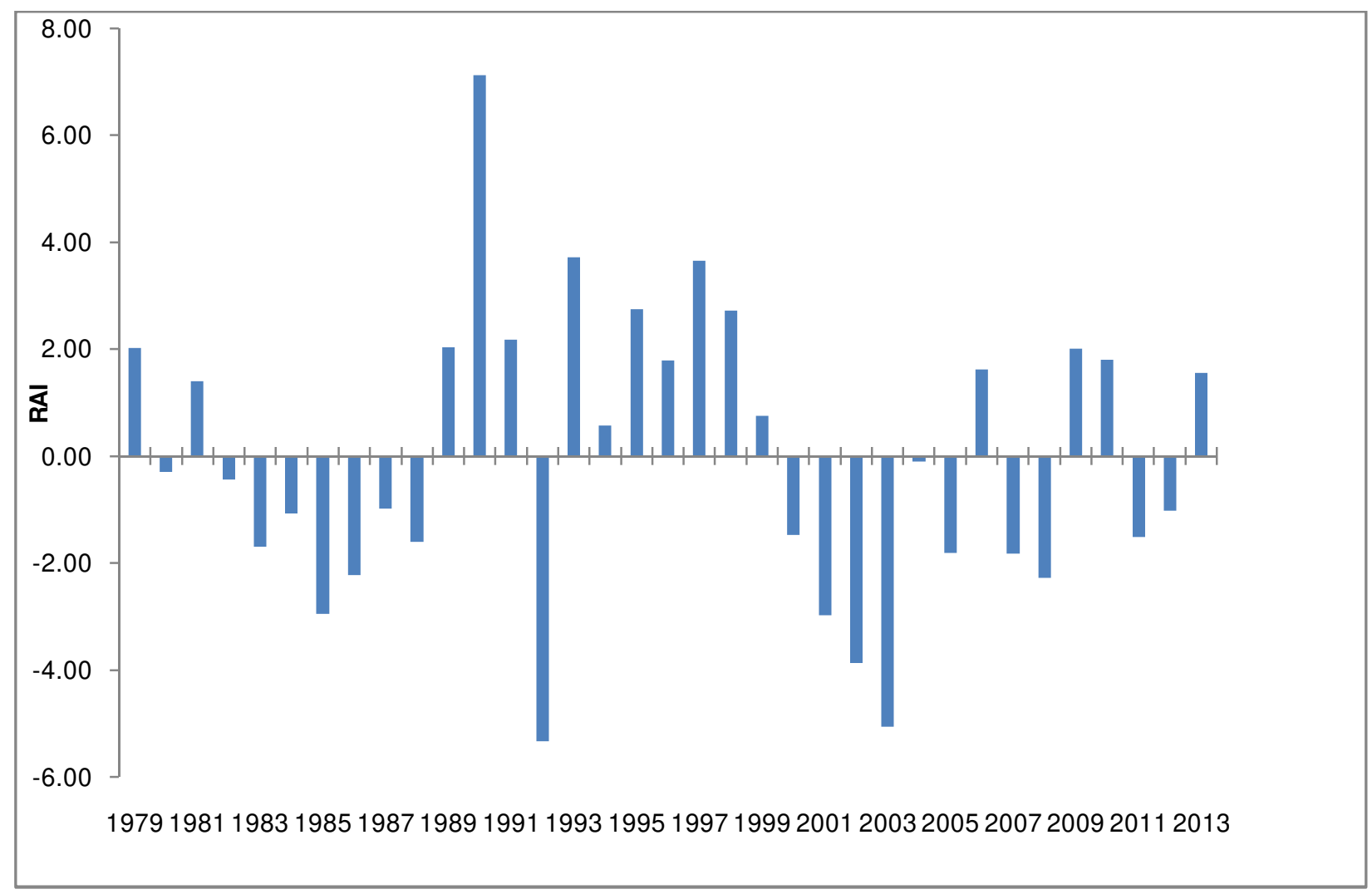

Fig.3: Rainfall Anomaly Index for the study area

Figure 4 shows the spatial distribution of the RAI for the entire study area. It is also observed that the average RAI for the period was negative for the entire area. The northeast portion has a lower RAI than in the southwest. The entire study area falls under the dry RAI category.

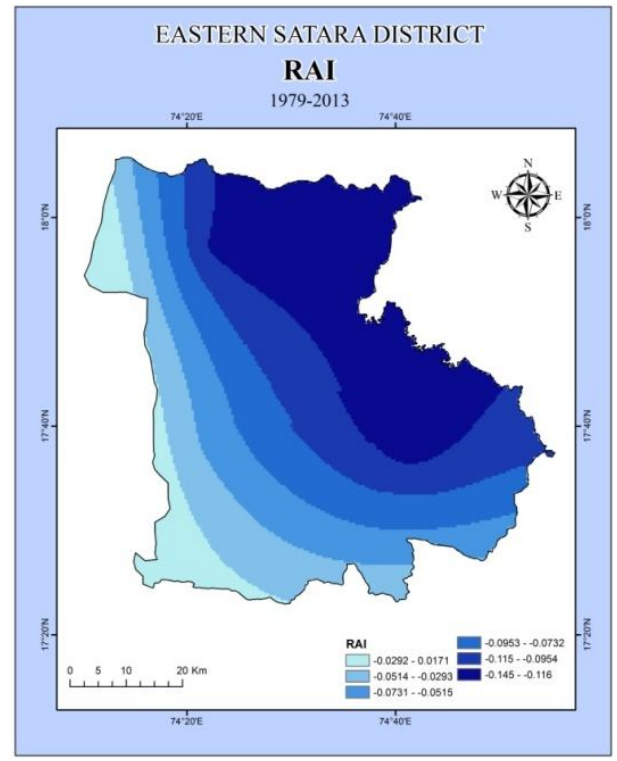

Fig.4: Spatial distribution of the rainfall anomaly index 


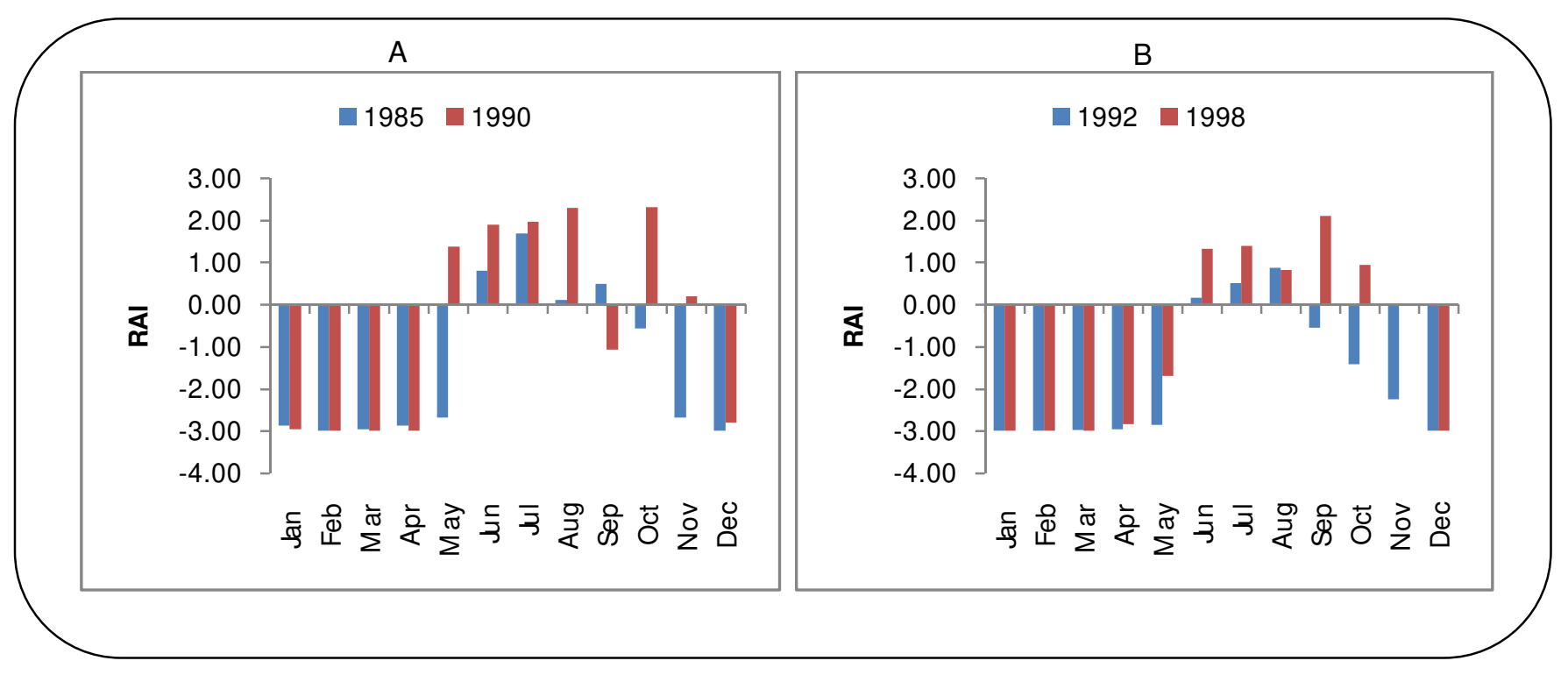

Fig.5 A \& B: Monthly RAI of the study area: rainy years and dry years

To evaluate the distribution of rainfall in the study area during years of extreme anomalies, the monthly RAI of specific years were analyzed (Figure5A\&B). The two most humid indexes (1990 and 1998) and the two driest ones (1985 and 1992) of the historical series were chosen. The driest years in 1985 in the historical series presented only average precipitation in July remaining rainy months are of acute stress of precipitation, and another dry year 1992 depicts same conditions. 

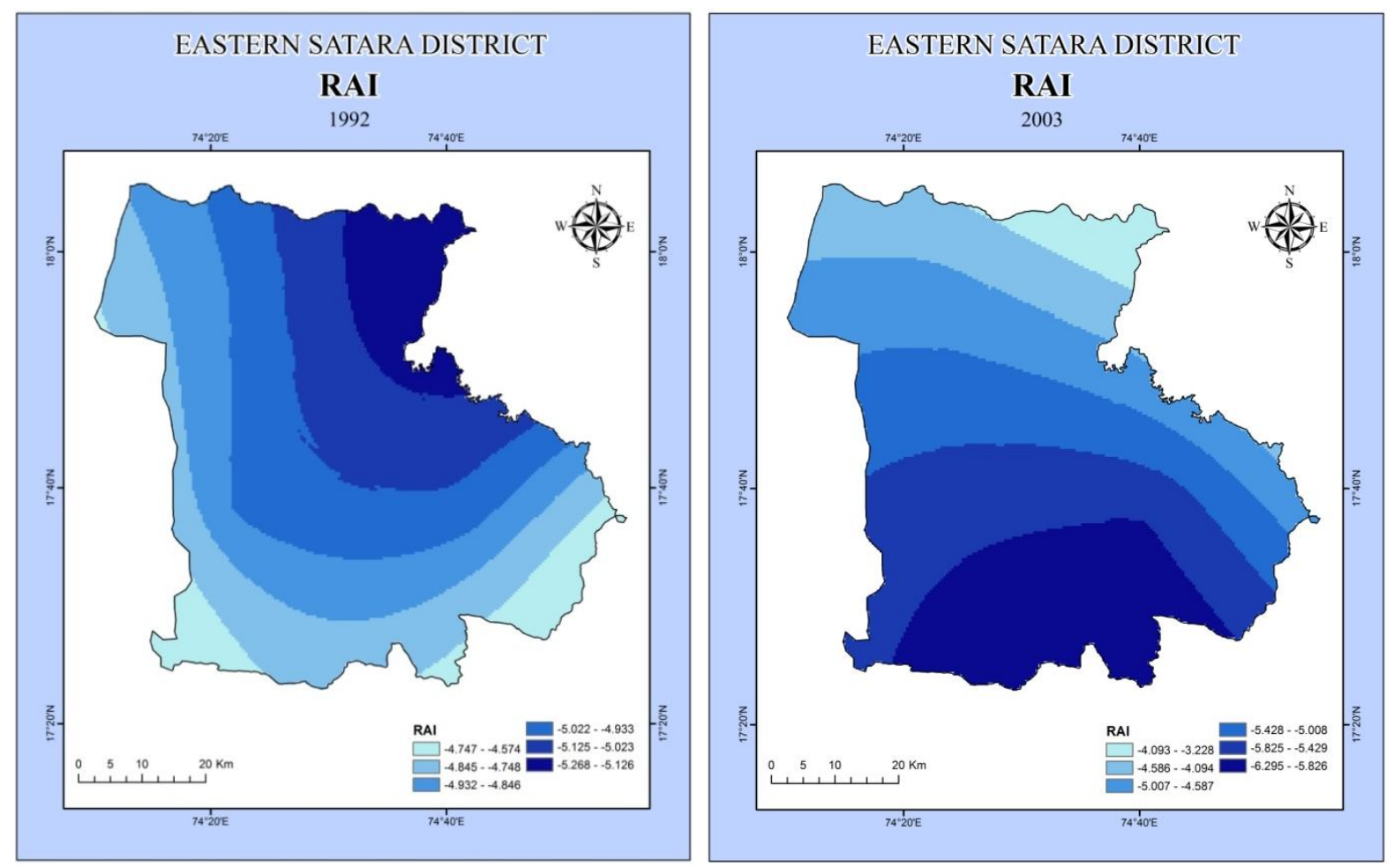

Fig. 6: Specialization of RAI in the most extreme years: 1992 (A) and 2003 (B)

Year 1992 and 2003 are extreme negative anomalies (figure6A\&B). It is clearly identified that the year 1992 is the most negative anomalies year in the historical series, the RAI of this year which is -5.33 , this is under extremely dry category. The northeast part of the study area presented extreme negative anomalies. For the year 2003, which has is most negative anomalies concentrated in southern portion of the study area; the RAI of this year is -5.06 which falls in extremely dry category.

\section{Conclusion}

The present investigation attempts to identify and assess the intensity and frequency of drought in the eastern part of the Satara district. The RAI method was utilized to assess the drought severity in the study area. The distribution of rainfall shows that 1992 and 2003 have minimum average rainfall which represents 918 and $709 \mathrm{~mm}$ respectively. The rainfall station 1, 4 and 7 are having the highest annual average rainfall whereas the lowest annual average rainfall dominants at 11 and 12 station in the study area. The historical series data has 16 rainy years and 19 dry years, with 1990 as the wettest year and 1992 as the driest. The overall investigation reveals that the eastern and southern part of the study area is prone to dry conditions. RAI is facilitated to make the comparison between precipitation deviations in different regions and it also assess the intensity and frequency of drought it consequently RAI will useful to indicate rainfall station history of a particular location. The present study will be helpful to demarcate potential sites of drought and useful for planning and mitigation purpose.

\section{Reference}


Dai A (2011) Characteristics and trends in various forms of the Palmer drought severity index during 1900-2008. J Geophys Res 116. https://doi.org/10.1029/2010jd015541

Fernandes DS, Heinemann AB, Paz RL, Amorim AO, Cardoso AS. Índices para a Quantificação da Seca. Santo Antônio de Goiás, Embrapa Arroz e Feijão, 2009.

Freitas mas. Um sistema de suporte à decisão para o monitoramento de secas meteorológicas em regiões semiáridas. Rev. Tecnol. 2005; (suppl 19): p. 84-95.

IonitaM, Scholz P, Chelcea S (2016) Assessment of droughts in Romania using the standardized precipitation index. Nat Hazards 81:1483- 1498. https://doi.org/10.1007/s11069-015-2141-8

Jain, S.K., Keshri, R., Goswami, A., Sarkar, A., 2010. Application of meteorological and vegetation indices for evaluation of drought impact: a case study for Rajasthan, India. Nat. Hazards 54, 643-656.

Kamble, M. V., Ghosh, K., Rajeevan, M., \& Samui, R. P. (2010). Drought monitoring over India through normalized difference vegetation index (NDVI). Mausam, 61, 537-546.

Keyantash J, Dracup JA (2002) The quantification of drought: an evaluation of drought indices. Bull Am Meteorol Soc 83:1167-1180

McKee TB, Doesken NJ, Kleist J (1993) The relationship of drought frequency and duration to time scales. In: Proceedings of the 8th Conference on Applied Climatology, vol 22. American Meteorological Society Boston, MA, pp 179-183

Palmer WC (1968) Keeping track of crop moisture conditions, nationwide: the new crop moisture index. Weatherwise 21:156-161. https://doi.org/10.1080/00431672.1968.9932814

Rajasekaran E, Das N, Poulsen C, Behrangi A, Swigart J, Svoboda M, Entekhabi D, Yueh S, Doorn B, Entin J (2018) SMAP soil moisture change as an Indicator of drought conditions. Remote Sens 10:788. https://doi.org/10.3390/rs10050788

SabrineJemai, Amjadkallel and HabibAbida (2018) Drought distribution using the standard precipitation index: case of Gabes Basin, South Tunisia.

Sandholt I, Rasmussen K, Andersen J (2002) A simple interpretation of the surface temperature/vegetation index space for assessment of surface moisture status. Remote Sens Environ 79:213-224. https:// doi.org/10.1016/s0034-4257(01)00274-7

Schuman, A. (2007). A multi-criteria approach in drought risk assessment. Lecture materials; Institute of Hydrology, Ruhr University, Bochum

Shafer BA, Dezman LE (1982) Development of a surface water supply index (SWSI) to assess the severity of drought conditions in snowpack runoff areas. Western Snow Conference, Reno, Nevada

Van Rooy M (1965) A rainfall anomaly index independent of time and space. Notes 14:6

W. C. Palmer, "Meteorological Drought", U.S. Weather Bureau Manuscript No. 45 58pp February, 1965. 
Wells N, Goddard S, Hayes MJ (2004) A self-calibrating Palmer drought severity index. J Clim 17:2335-2351. https://doi.org/10.1175/1520- 0442(2004)0172.0.co;2

Wilhite DA (2000) In: Wilhite DA (ed) Drought: a global assessment, vol 1. Routledge, London, pp 3-18

WMO and GWP (World Meteorological Organization and Global Water Partnership) (2016) Handbook of drought indicators and indices In: Svoboda M, Fuchs BA (eds) Integrated drought management Programme (IDMP). Integrated drought management tools and guidelines series 2, Geneva

WMO-No. 989, (2005). Climate and land degradation. World Meteorological Organization, WMO.ISBN92-63-10989-3: www.wmo.int/web/wcp/agm/agmp.html

Zhao S, Cong D, He K, Yang H, Qin Z (2017) Spatial-temporal variation of drought in China from 1982 to 2010 based on a modified temperature vegetation drought index (mTVDI). Sci Rep 7:17473. https://doi.org/10.1038/s41598-017-17810-3 
Figures

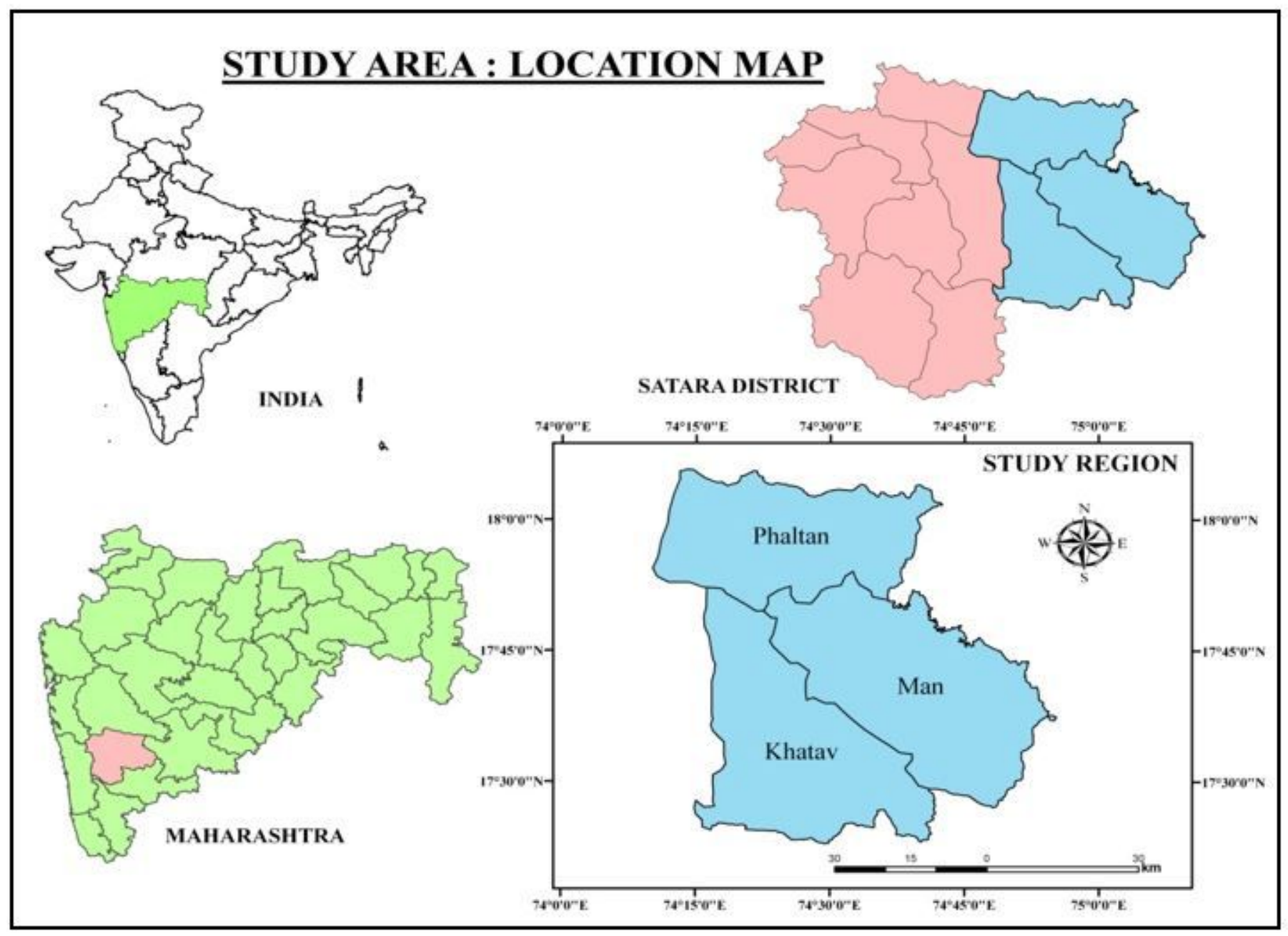

Figure 1

Geographical Location of the Study Area 


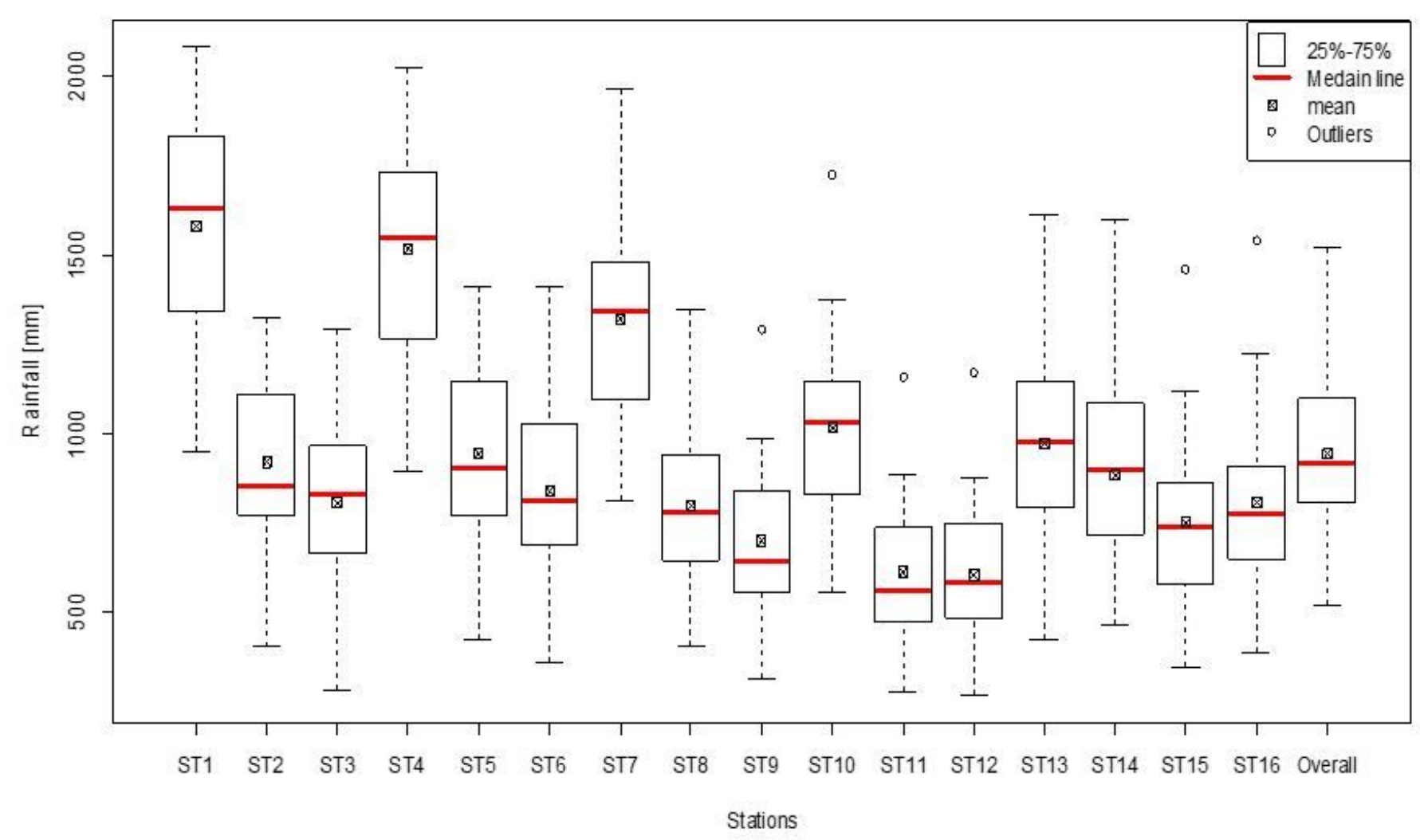

Figure 2

Box plot of annual rainfall variability for every station and overall study area (1979-2013) 


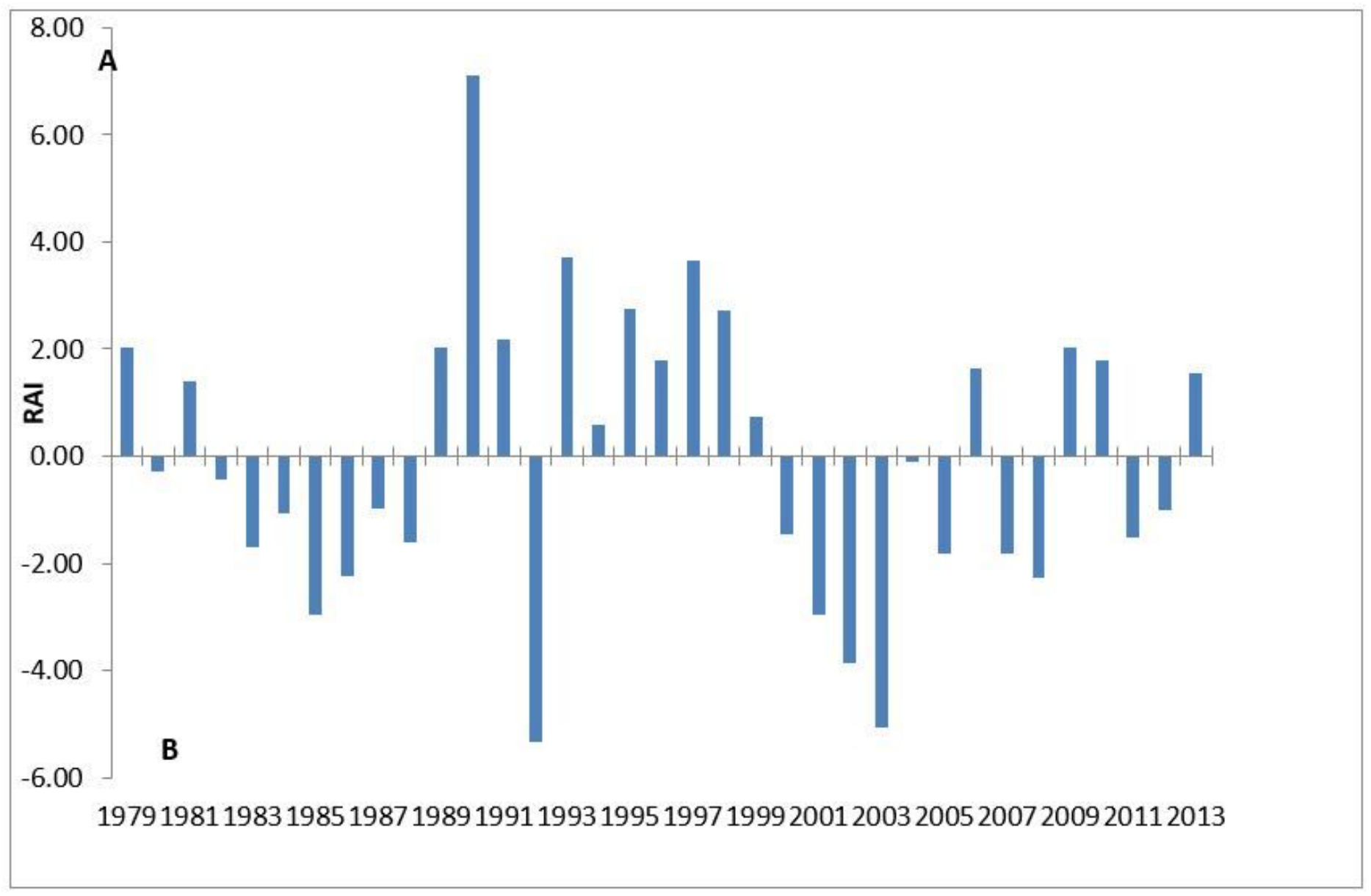

Figure 3

Rainfall Anomaly Index for the study area 


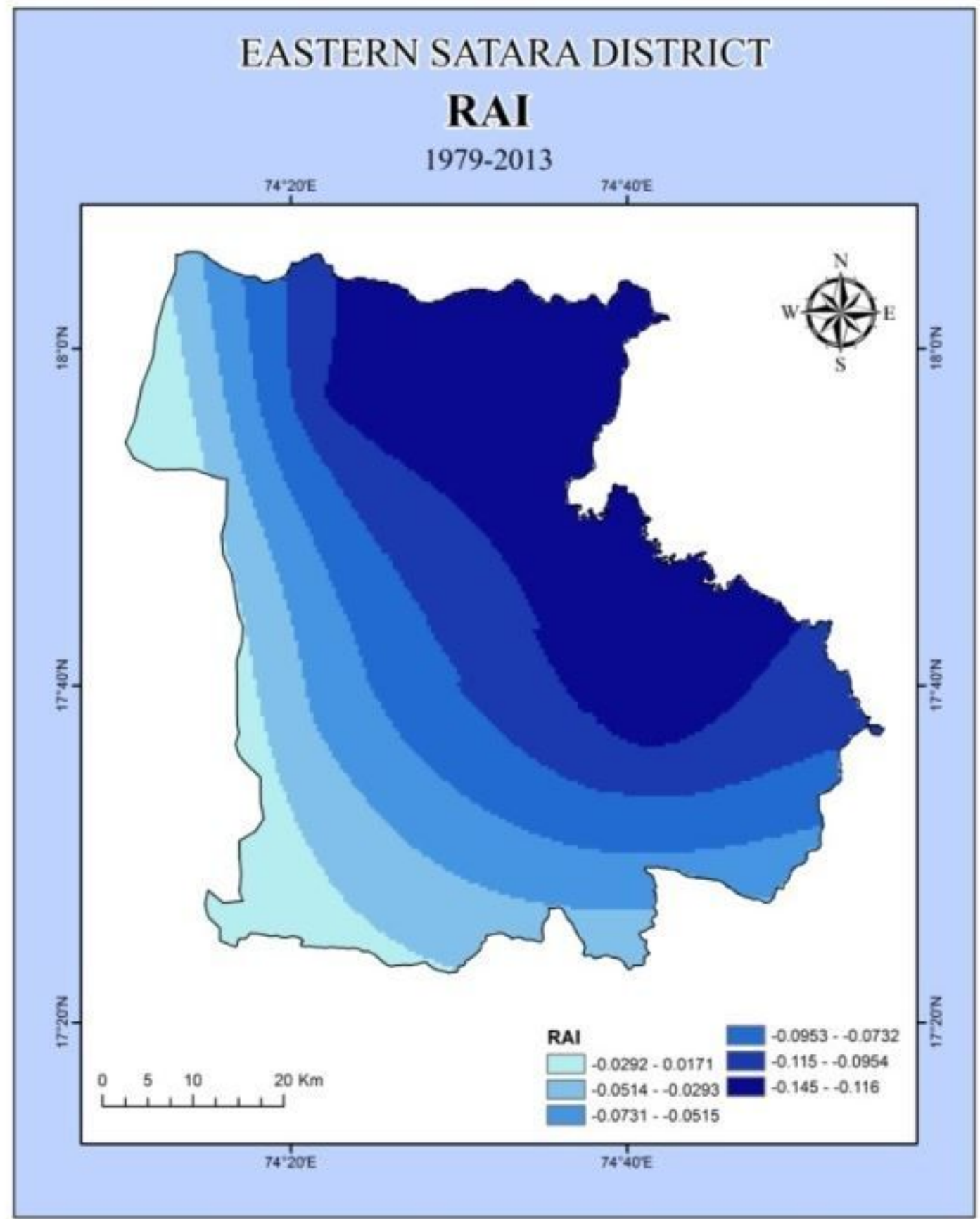

Figure 4

Spatial distribution of the rainfall anomaly index 

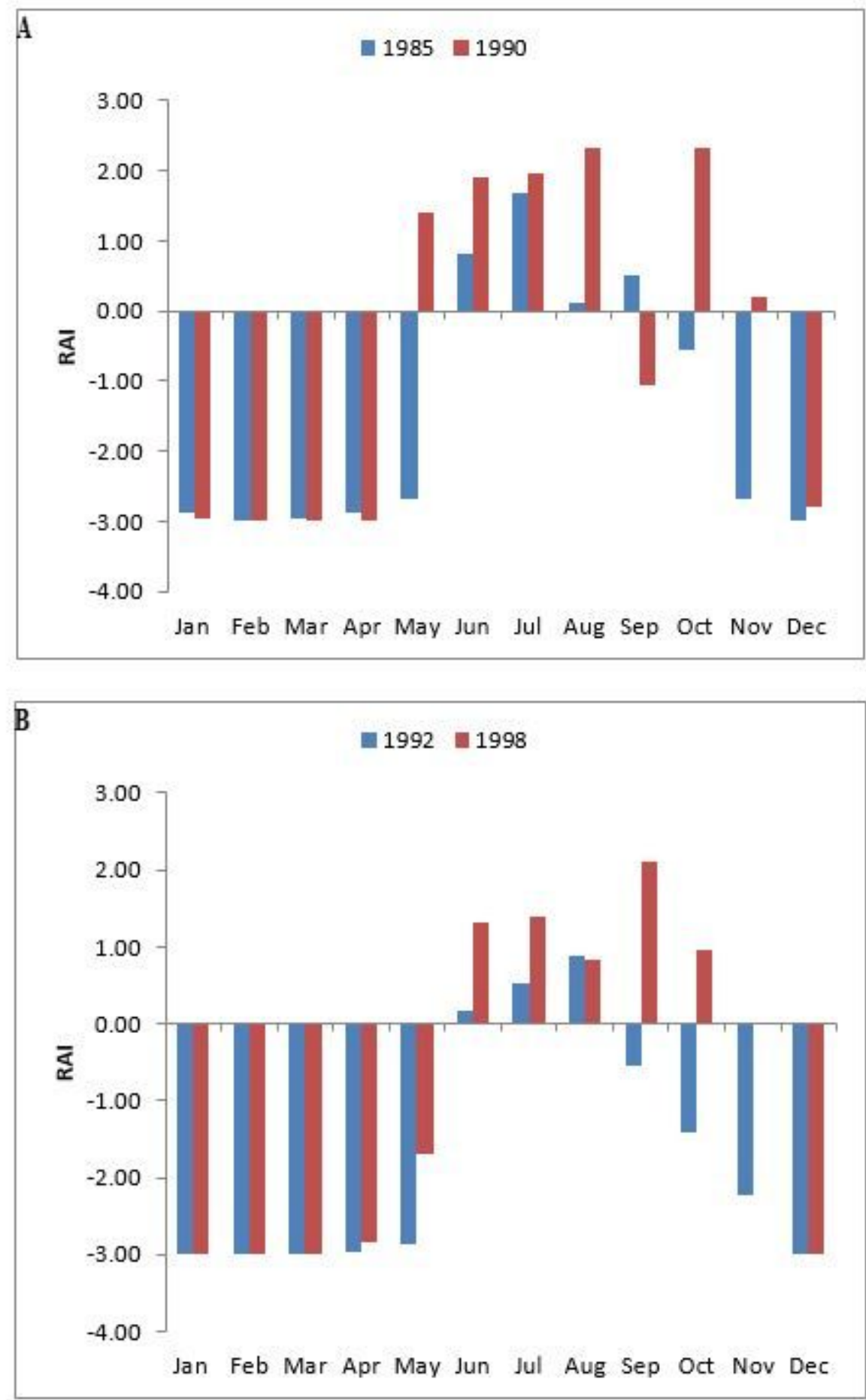

Figure 5

A \& B: Monthly RAI of the study area: rainy years and dry years 

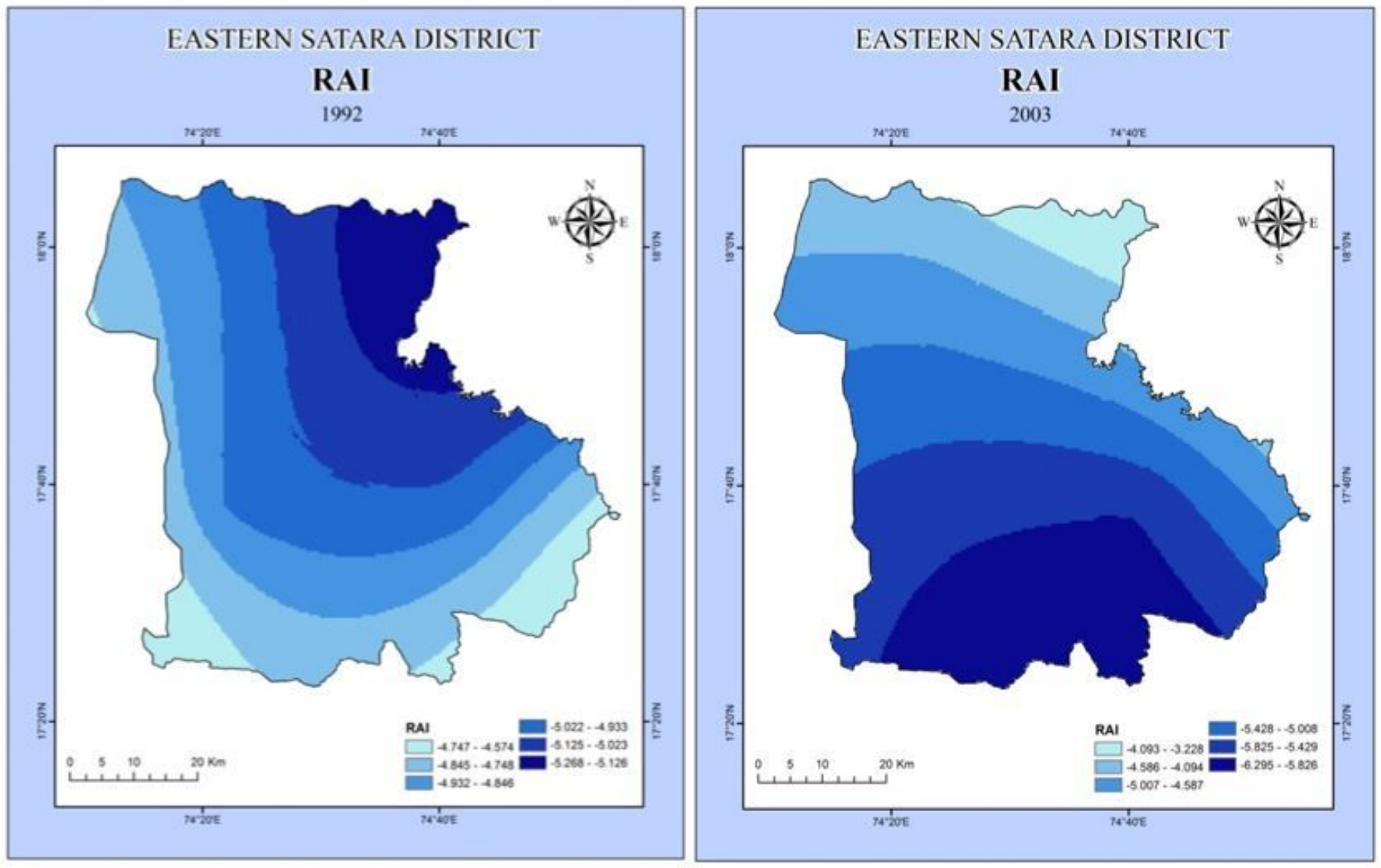

Figure 6

Specialization of RAl in the most extreme years: 1992 (A) and 2003 (B) 